\title{
Personality disorder: the doctor's most intractable dilemma
}

\author{
Brian Ferguson \& John Milton
}

Ir J Psych Med 2000; 17(1): 3-4

People who suffer from personality disorder present in most medicai settings and make heavy demands on health services. As conventionally defined, the disorder refers to a broad grouping of abnormal personalities and includes among others, the borderline, the dependent and paranoid, as well as the more commonly recognised 'psychopath'. Behavioural manifestations vary. They may take the form of impulsive overdosing, manipulation, aggression or destructive dependency on others. Doctors do not share a common understanding of the condition but this is no longer tenable. Psychiatric staff have responsibilities for the care and treatment of such individuals and are increasingly being seen as holding some responsibility for the their behaviour, as in the case of suicide or harm prevention.1 This process has been an insidious one and relies to a great extent on the imposition of the medical model on personal behaviour. It is timely therefore to take stock and clarify our response to these disorders.

The clinical use of the concept of personality disorder has been heavily criticised on the basis of its pejorative overtones and the inevitable subjective bias of the assessor. It is a diagnosis based on personal defects of character which can rarely be attractive to the person to whom it is attached. Early research ${ }^{2}$ painted a dismal picture and suggested that specific personality disorder diagnoses were highly unreliable. If trained psychiatrists and psychologists could not agree on the presence or absence of specific personality disorders, how could general practitioners and non-clinicians be expected to distinguish between these conditions and the more general forms of mental illness, such as schizophrenia or mood disorders? The results of this public confusion are seen regularly in newspaper reports of crime, including homicide, where healthcare services have been involved. Professional failure to distinguish between these conditions is mirrored in public discussion and it is not unusual to find the words psychopathic and psychotic used interchangeably.

Research in the field of personality disorder has, nonetheless, made considerable headway over the past decade. The World Health Organisation/ADAMHA studies ${ }^{3}$ have disproved the contention that the diagnosis of personality is culture bound and it is now possible to increase reliability to levels that are considered acceptable for the main psychiatric conditions. As yet, these structured procedures are too cumbersome for everyday clinical use, but the principle of good reliability has been established. The critical issues are now those of establishing

* Brian Ferguson, Consultant Psychiatrist, Stonebridge Centre, Cardiff Street, Carlton Road, Nottingham, NG3 2FH, England. John Milton, Lecturer in Forensic Mental Health, Arnold Lodge, Cordelia Close, Leicester, LE5 0LE, England.

"Correspondence

SUBMITTED: JUNE 14, 1999. ACCEPTED: SEPTE.MBER 10, 1999. validity, training and recognition.

Despite the recent advances in establishing reliability, there is an ongoing failure to test the validity of the concept. It is unfortunate that, when looking at this issue, researchers have relied primarily on descriptive analysis of highly selected groups such as borderline. Insufficient attention has been paid to the essential nature of these conditions and their implications for rapidly changing health services. Disagreement abounds as to whether such individuals should be offered 'treatment' and the diagnosis is frequently conflated with the issue of personal responsibility. This may result partly from an extrapolation of the Freudian dictum that an individual does not act in free will and without motive. ${ }^{+}$Adult behaviour does not emerge fully formed, but occurs in the context of a complex network of previous thought and emotional experience, both conscious and unconscious. For some, this reasoned argument means that the individual lacks free will and therefore cannot 'help' avoid their behaviour even in adulthood. The notion that behaviour is compelled in this manner is clearly absurd, ${ }^{5}$ even when linked to the experience of appalling suffering, as in the case of an individual who has previously endured the effects of physical or emotional abuse.

It is however, very hard for a practitioner to witness distress and not respond in a sympathetic manner. Government structures are not immune to this process. The UK Home Office Working Party on Psychopathic Disorder ${ }^{6}$ commissioned a study by Coid and Dolan which examined the published English language work on the treatment of personality disorder. ${ }^{7}$ In their detailed review, they came to the conclusion that research in this area had failed to prove or disprove the efficacy of any particular therapeutic intervention.

Nonetheless, the report went on to recommend that a variety of treatments and services should be made available to the personality disordered. Such a development takes matters to the point whereby doctors may be seen to have responsibilities for the behaviour of others, despite the failure to identify evidence-based therapeutic interventions. Establishing the validity of the concept is therefore essential.

The medicalisation of personality disorder is not new and some might argue that such difficulties arise with the established mental illnesses such as schizophrenia. "The concept of disease which is appropriately applied to those conditions requires a number of essential criteria to be met, including the identification of a pathogenic process. Personality disorder clearly fails such a test as the argument for its existence is primarily tautological. Subjects are diagnosed as suffering from personality disorder because of a collection of behaviours and dispositions. They engage in behaviours such as impulsive self-harm and aggression because they are personality disordered. Psychological 
theories of development may seek to elaborate on the detail, but in essence they are untestable in the Poperian sense," and therefore must be considered unscientific. The disease model cannot be applied sensibly.

Other factors are offered as corroborative evidence for the disease model. The recent studies on the inheritance pattern of dissocial traits is but one example. The fact that personality characteristics are inherited has been known to mankind for millennia. Familial hair colouring and baldness follow a similar pattern but hopefully are not seen as evidence of a pathological process. The necessary features of a disease model, using Virchowian principles, ${ }^{10}$ include a clear establishment of course and prognosis, both of which are linked to identified pathology. Again, despite the anecdotal evidence, the diagnosis of personality disorder lacks such support.

The assertion that any condition associated with discomfort, pain, disability or death, which is regarded by doctors and the public at large as the responsibility of the medical profession and therefore constitutes a disease, ${ }^{11}$ is far too imprecise for the modern age. Those who conceptualise sexual deviancy, such as paedophilia, as a disease state which requires treatment in medical settings thereby become most vulnerable when the public mood changes. An alternative understanding of these conditions using a social model is required.

If science has been so singularly ineffective in supporting the disease concept of personality disorder, what other clinical paradigms are useful? In many respects, the definition provided by Jaspers is still the most effective. ${ }^{12}$ Such individuals are best conceptualised as being at the extreme end of normal human variation. They differ from the rest of the population only in the degree to which they are affected by traits shared by all. Accepting this conclusion leaves us with a dilemma. It implies that socially unacceptable behaviour in its broadest sense must not be seen as an acceptable sign of illness. If driving while inebriated is not regarded as a valid expression of an 'alcohol disease,' then how can overdosing or aggressive conduct be seen as legitimate expressions of personality disease? There is no escaping the need to make moral judgements. Many, however, shy away from distinguishing between good and evil conduct and regard the introductions of ethical considerations as a dangerous precedent. Remarkably, the recently published policy of the Royal College of Psychiatrists on the assessment of risk of harm to others makes no mention of patient responsibility. ${ }^{13}$

But what are the consequences of the agnostic medical approach? In the real world moral judgements are being made anyway and it is worthy of note that only $10 \%$ of forensic psychiatrists emphatically endorse the view that psychiatry has a duty to provide treatment for psychopathic personality. ${ }^{14}$ The diagnosis may therefore be used to facilitate or avoid issues of personal responsibility particularly where mandatory life sentences for a wide variety of offences become the norm.

If it is right for people suffering from personality disorder to have diminished responsibility in criminal cases, ${ }^{1,5}$ should the same not apply in civil cases such as the failure to fulfil a contract? Where personality disorder is seen as a mental disease, there is little rationale for punishing individuals who have no alternative but to commit crimes as a direct result of their illness. If the disease concept does not apply then it is hard to argue that such individuals should be protected from their behaviour. The ultimate in politi- cal correctness would otherwise be a situation in which evil is treated as a disease and those who give expression to it are regarded as not being fully responsible for doing so. As in Samuel Butler's satirical Ereholm, bad conduct would be seen to be the result of either pre or postnatal misfortune for which treatment rather than punishment is required. ${ }^{16}$

Politicians and the lay public are not interested in phenomenological detail and cannot understand why patients are refused treatment when there is clearly something wrong. As a result, the UK government now proposes to introduce a form of medical internment without crime. ${ }^{17}$ Presumably psychiatrists and psychologists will thereby become an integral component of a new mechanism of social control. Indefinite detention on the basis of actuarial risk could be introduced under the guise of treatments which have not successfully met the challenge of rigorous scientific assessment.

The present use of personality disorder in clinical, managerial and forensic settings is potentially dangerous and lacks clarity. It functions as a menu into which interested parties can dip to sort out unrelated problems. Where the penal system is seen as too punitive with a high risk of suicide, the concept of personality disorder may help some to evade punishment while others may have the full weight of the law applied. Parasuicide and related behaviours are still seen by too many as a legitimate expression of distress despite the wider impact on society and the health services. Psychiatry and psychology can no longer afford such plasticity. The wherewithal to investigate the validity of the concept of personality disorder is now available to us. The impact of specific interventions can be established through randomised controlled trials which are required in every other aspect of medicine. The rules of evidence-based research must be adhered to and the issues of responsibility divorced from diagnosis. Personality disorder may explain, but never excuse. It is only by rediscovering science that we can hope to make any real progress in this area.

\section{References}

1. Coid J. Dangerous patients with mental illness: increased risks warrant new policies, resources and appropriate legislation. BMJ 1996; 312: 965-6.

2. Walton $\mathrm{H}$, Presley $A$. Use of a category system in the diagnosis of abnormal personality. Br J Psychiat 1973; 122, 259-68.

3. Loranger A, Sartorius N, Andreoli A et al. The International Personality Disorder Examination. The World Health Organisation Alcohol, Drug Abuse and Mental Health Administration International Pilot Study of Personality Disorders. Arch Gen Psych 1994; 51: 215-24.

4. Freud S. The psychopathology of everyday life. London: The Hogarth Press and the Institute of Psychoanalysis, 1901

5 . Flew AGN. Crime or disease? Br J Sociology 1954; 49-62.

6. Report of the Department of Health and Home Office Working Party on Psychopathic Disorder, 1994.

7. Dolan B, Coid J. Psychopathic and antisocial personality disorders: treatment and research issues. London: Gaskell, The Royal College of Psychiatrists, 1993. 8. Kraupl Taylor $F$. The concepts of illness, disease and morbus. Cambridge: University Cambridge, 1979.

9. Sowerby P. The doctor, his patient, and the illness: an appraisal. J R Coll Gen Pract 1977; 27: 583-9.

10. Kendall RE. The major functional psychosis: are they independent entities or part of a continuum? Philosophical and conceptual issues underlying the debate. In: Kerr A, McClelland $\mathrm{H}$ (eds). Concepts of medical disorder, a continuing debate. London: Gaskell, Royal College of Psychiatrists, 1991. 11. Goodwin D, Guze S. Psychiarric diagnosis. 2nd ed. Oxford University Press, 1979.

12. Jaspers K. General Psychopathology. Transl by: Hoenig J, Hamilton M. Manchester University Press, 1962.

13. Royal College of Psychiatrists. Assessment and clinical management of risk of harm to other people. Council Report CR53. London: Royal College of Psychiatrists, 1996.

14. Cope RV. A survey of forensic psychiatrists. J Forensic Psychiatry 1993; $4(2): 215-36$.

15. Gunn J, Taylor P (eds). Forensic psychiatry: clinical, legal and ethical issues. Oxford: Butterworth Heinemann, 1995.

17. Statement of the Secretary of State for the Home Department (M Jack Straw). House of Commons Harsard Debates, London, United Kingdom, Feb $15,1999$. 